\section{Condutas em psiquiatria}

Editores: Táki A. Cordás e Ricardo Alberto Moreno

Editora Lemos, 2001, 4ª edição, 421 págs.

ISBN 85-7450-069-6

Capítulos: Princípios gerais da ação de fármacos; Aspectos éticos; Exames complementares e a investigação clínica em psiquiatria; Emergências em psiquiatria; Drogas que causam sintomas psiquiátricos; Antipsicóticos; Antidepressivos tricíclicos; Tratamento dos efeitos colaterais de medicamentos psicoativos; Inibidores da monoaminoxidase; Estabilizadores do humor; Benzodiazepínicos e hipnóticos; Interações medicamentosas em psiquiatria; Eletroconvulsoterapia; Dependências químicas; Terapêtica dos transtornos associados à epilepsia; Inibidores seletivos da recaptação de serotonina e antidepressivos de nova geração.

Poderíamos nos perguntar se existe necessidade de mais um livro de psicofarmacoterapia, tendo em vista a existência de ótimos livros estrangeiros. Acreditamos que a resposta é afirmativa: sim, necessitamos de obras de autores nacionais, pois, de modo geral, existem duas lacunas importantes nos livros traduzidos: primeiro há um certo desencontro das drogas disponíveis no Brasil e as drogas disponíveis nos outros países; segundo, a transposição direta dos resultados dos estudos e da experiência clínica com uma população diferente (cultura, genética etc.) para nossos pacientes pode acarretar algumas discrepâncias.Nessa linha, livros de psicofarmacoterapia escritos conjuntamente por pesquisadores e clínicos brasileiros são fundamentais para a prática clínica, pois aliam o filtro crítico da literatura científica nacional e internacional com a experiência clínica no Brasil. Em particular, o livro "Condutas em psiquiatria" é um texto singular sob vários aspectos: escrito por vários autores, mantém uma coerência e consistência interna ao longo de todo o volume; é intencionalmente voltado para ser um manual de consulta na prática psiquiátrica do dia-a-dia; e consegue integrar a experiência clínica dos autores com a melhor e mais atualizada evidência científica disponível.

Uma característica importante do livro é que se trata de uma obra escrita por especialistas e pesquisadores para o psiquiatra clínico, com leitura fácil e agradável, sem jargões técnicos, conseguindo escapar da tentação de escrever um livro para psiquiatras clínicos, mas preocupado principalmente com a opinião dos colegas especialistas (Christodoulou, Current Opinion Psychiatr 1998;11:493). Por exemplo, o capítulo Princípios gerais da ação de drogas (C. Gorenstein \& $\mathrm{T}$. Marcourakis) é de leitura agradável e aborda o tema de modo claro e completo, fornecendo uma visão dos principais tópicos e ressaltando a importância clínica do tema.

Em relação aos capítulos, é interessante a preocupação dos editores em incluir capítulos de temas extremamente importantes, mas nem sempre abordados nesse tipo de publicação, como: Aspectos éticos, Exames complementares e Investigação clínica em psiquiatria, Drogas que causam sintomas psiquiátricos, Terapêutica dos transtornos mentais associados à epilepsia e eletroconvulsoterapia. Essa nova edição mantém a mesma divisão de capítulos que as anteriores, embora com novos acréscimos e atualizações desde a última edição. Essa constante atualização dos capítulos pode ser observada por meio da referência a novas drogas antiepiléticas (p.ex., vigabatrina e lamotrigina) e novas drogas antidepressivas (p.ex., milnacipran).

$\mathrm{O}$ capítulo dedicado às interações medicamentosas incorpora, em tabelas de fácil consulta, os mecanismos de interação potencias de drogas, como por exemplo entre topiromato e lamotrigina com outros anticonvulsivantes estabilizadores de humor. No capítulo sobre benzodiazepínicos, a presente edição é acrescida do tópico sobre hipnóticos, que passa a incluir informações sobre as medicações hipno-indutoras não-benzodiazepínicas, como zolpidem, zopiclone e zaleplon. Entretanto, uma lacuna em relação aos ansiolíticos é a ausência de referência a drogas ansiolíticas não-benzodiazepínicas, em particular a buspirona, mesmo existindo questionamentos quanto a sua eficácia clínica (Andreatini R et al, Rev Bras Psiq 2001;23(4):233-42). Outra droga que poderia ser abordada com mais detalhes é o penfluridol, um antipsicótico típico de depósito, mas de uso oral, o que lhe confere uma característica ímpar. Em relação ao conteúdo, em edições futuras, os editores poderiam considerar a possibilidade de acrescentar dois novos capítulos: um sobre os distúrbios comportamentais e cognitivos em pacientes idosos e outro sobre os fitoterápicos empregados em psiquiatria (p.ex., Hypericum perforatum), abordando sua eficácia (ou ineficácia), efeitos adversos, interações etc. (ou cada fitoterápico poderia ser descrito dentro de cada capítulo relacionado a seu emprego clínico).

Em relação à parte editorial, o livro é apresentado em um formato agradável, de fácil manuseio. Entretanto, alguns pontos que merecem consideração em próximas edições são: atenção na impressão, pois todos os acentos [ ] foram substituídos por ['] (provavelmente por problemas de software), uma ordenação dos capítulos por temas relacionados (p.ex., antidepressivos tricíclicos, IMAO, IRSR e ATD de nova geração). Outro detalhe que facilitaria o leitor seria a introdução, em alguns capítulos, das referências no corpo do texto. Por exemplo, encontramos certas dificuldades em relacionar as informações relativas ao EEG às referências bibliográficas.

Portanto, esse livro vem tornando-se um texto indispensável para o psiquiatra experiente e para o iniciante e, por meio de uma linguagem clara e concisa, facilita a busca e a localização da informação necessária. Como escrito no prefácio por Del Porto "quatro edições em oito anos já atestam (...) que este livro se constitui em um autorizado guia de condutas em nossa especialidade". Mais ainda, o lançamento dessa quarta edição de "Condutas em psiquiatria" demonstra a excelente acolhida e o respeito que esse manual obteve entre os profissionais que atuam na área dos transtornos mentais.

Roberto Andreatini

Departamento de Farmacologia da Universidade Federal do Paraná (UFPR)

Dirceu Zorzetto Filho

Departamento de Medicina Forense e Psiquiatria da UFPR 